\title{
Impact of Video-games on Social Intuition among Teenagers
}

\author{
Chandrashekhar D.M. ${ }^{1}$, Ravindra P.N. ${ }^{2}$, Prashanth Babu ${ }^{1}$ \\ ${ }^{1}$ Assistant Professor, ${ }^{2}$ Professor and Head, epartment of Physiology, Gadag Institute of Medical Sciences, Gadag
}

\begin{abstract}
Background: Playing games is not only a favorite past time but it is also an inherent behavior in human beings that promotes cognitive and social development. With changing lifestyle, outdoor games have been replaced by electronic games like video-games, which are fast gaining popularity among teenagers, with the prevalence rate being as high as $75 \%$ in some of the industrialized countries. The popularity of video-games has raised concern over their possible impact on the social and emotional development of teenagers who regularly indulge in video-gaming
\end{abstract}

Aims and Objectives: The aim of the present study was to assess the impact of regular competitive videogaming on social intuition among teenagers.

Materials and Method: The present study was conducted in GIMS, Gadag, after being cleared by the Ethical committee. Fifty healthy teens in the age group of 17-19 years who regularly played competitive video-games acted as subjects and fifty age and gender matched students were controls. Information related to type and duration of video-gaming was assessed using comprehensive questionnaire. Social intuition was evaluated using emotional styles questionnaire. Comparison between the groups was done using students t-test. Effect size was calculated.

Results: Social intuition was found to be decreased in teenagers who regularly played competitive videogames, when compared to their peers who didn't play video-games. The difference was statistically significant $(\mathrm{P}<0.05)$.

Conclusion: Competitive video-gaming has a negative effect on social intuition among teenagers.

Keywords: Video-games, Teenagers, Social intuition.

\section{Introduction}

A play can be defined as a voluntary activity that is intrinsically motivated, involves active physical and mental engagement and results in a reward. Play often has no extrinsic goals; it is fun, often spontaneous and performed for self-amusement and recreation. Play during

\section{Corresponding Author. Prashanth Babu}

Assistant Professor, Department of Physiology, Gadag

Institute of Medical Sciences. Gadag

e-mail: drprashantbabu@yahoo.com

Phone Number: 9741653659 early childhood is not just a past-time but a valuable tool for learning social-emotional, cognitive, language and self-regulation skills that help in the development of a pro-social brain. Play helps the child to acquire valuable skills like problem solving, collaboration and creativity that are later critical for adult success. ${ }^{1}$

Social play behavior also referred to as play fighting, is a form of social behavior extremely common in many mammals particularly during early childhood. This form of play helps in the development of various social skills that are valuable during adulthood. One important function of social play behavior is to facilitate the development of a rich and flexible social repertoire that is the trigger for social development. ${ }^{2}$ 
The drive to play and engage in games is not just limited to childhood and early developmental years; it also tends to continue into adolescence and adulthood as well. However with the changing life-style the nature of the games has changed dramatically. Teenagers nowadays have started taking a liking towards electronic games like video-games, as is very much evident from the fact that the prevalence rate of video-gaming among teenagers is as high as $75 \%$ in some of the industrialized countries. $^{3}$

The easy accessibility and availability of smartphones and computers has exposed the majority of the population to the world of video-games and has fuelled their popularity among people of all age groups. However with teenagers being highly exposed to videogames, there is a need to assess the impact of videogames on the social behavior of teenagers who regularly indulge in video-gaming.

The crucial element that separates video-games from regular games is a total lack of direct social interaction. A video-gamer interacts with an electronic interface and rarely sees his opponent even in multi player games. With the advent of Role-playing games (RPG), a gamer controls a fictional character and interacts with other fictional characters online. Most video-games are totally devoid of direct face to face communication.

Face to face communication plays a vital role in the development of social skills as it engages complex neuronal networks-the mirror neuron system being one of them- that help in the development of empathy. Empathy enables us to perceive the emotion of others and allows us to tune ourselves to their emotional state. It helps us to understand the perspective of others and plays a critical role in development of interpersonal relations. These interpersonal interactions form the foundation of healthy social development. Empathy is the bridge that connects people and promotes prosocial behavior. $^{4}$

Recent research has shed light on the strong link between video-game exposure and isolated behavioral traits like empathy, morality and aggression. ${ }^{5}$ Exposure to violent video-games is shown to decrease not only empathy but related empathy-related concepts like sympathy and is believed to be implicated in delay of moral development. ${ }^{6}$

Teenagers who regularly play video-games seem to exhibit not only immature moral reasoning but also moral disengagement. ${ }^{7}$

However there are studies which have shown that action video-games may reduce rumination and may prove beneficial in depressed patients. ${ }^{8}$

Taking into consideration the available research on the influence of video-games on social behavior, the present study was under taken with the objective of assessing the social intuition of teenagers who regularly engaged in competitive video-gaming.

\section{Materials and Method}

The present study was conducted in Department of Physiology, GIMS, Gadag, after being cleared by the Ethical Committee of the Institute.

This was a cross sectional study done on teenagers whose age ranged from 17-19 years. Fifty teenagers who regularly played competitive video-games were enlisted in the study group and fifty age and gender matched teenagers who didn't play video-games were taken as controls.

Routine health check-up was done in all the volunteers who took part in the study. The aim and design of the study was explained in detail to all the volunteers and written informed consent was taken.

Inclusion Criteria: Healthy volunteers in the age range of 17-19 years.

\section{Exclusion Criteria:}

1. Students suffering from depression, anxiety or any other mental disorders.

2. Students who indulged in smoking, alcohol or usage of recreational drugs.

Method of collection of data: Duration and type of video-gaming among the video-gamers was found out using a detailed questionnaire. Only those teenagers playing competitive video-games were enlisted for the study.

Social intuition of the teenagers was assessed using "Emotional style questionnaire" designed by Richard Davidson et al., The Emotional Style Questionnaire is a measure of overall emotional health, it provides information about the six different dimensions underlying emotional health: The six dimensions being Outlook, Resilience, Social Intuition, Self-Awareness, Sensitivity to Context and Attention. 
The questionnaire for social intuition was chosen for the study. The subjects were asked to answer ten true/false questions and scoring was done based on the response. The maximum score being 10 and minimum being zero, the higher the score the more is the social intuition of the person. Social Intuition refers to one's degree of attunement to nonverbal social cues. People high on the Social Intuition dimension are adept at reading nonverbal cues such as facial expressions, body language or vocal intonation and infer social information from others' emotional states. People low on this dimension, on the other hand, has difficulty picking up and decoding subtle emotional signals.

The comparison between the two groups was done by students' t- test. Effect size was calculated to know the magnitude of influence of videogame on social intuition scores. All analysis was done in SPSS 16.

\section{Results}

The present study had a total of hundred participants who were divided into two groups:
Video-gamers: Those who played video-games on a regular basis $(n=50)$ and Controls: those who didn't play video-games $(\mathrm{n}=50)$.

In the present study the social intuition score in the control group was $6.54 \pm 1.83$ (Mean \pm SD) and the social intuition score among the video-gamers was $5.8 \pm$ $1.79($ Mean \pm SD) (Table 1, Graph 1).

The difference between both the groups was statistically significant ( ' $\mathrm{t}$ ' value $=2.039$ and $\mathrm{P}$ value $=0.044$ )

The average duration of video-gaming in the subject group was $1.24 \pm 0.91$ (Mean $\pm \mathrm{SD}$ ).

Correlation between social intuition scores and duration of video-gaming using Pearson's correlation coefficient yielded a ' $r$ ' value of -0.207 , though there was a negative correlation, it was not statistically significant $(\mathrm{P}$ value $=0.1492)$.

Effect size calculation showed moderate effect of video-games on social intuition score (Cohen's $d=$ $0.408)$.

Table 1: Social intuition score in controls and Video-gamers

\begin{tabular}{|c|c|c|c|c|}
\hline Controls Mean \pm SD & Video-gamers Mean \pm SD & t value & P value & Cohen's d (effect size) \\
\hline $6.54 \pm 1.83$ & $5.8 \pm 1.79$ & 2.039 & 0.044 & 0.408 \\
\hline
\end{tabular}

\section{Discussion}

For the sake of the study, Video-games were classified into two types- competitive video-games (where the participants compete with each other) and cooperative video-games (where participants co-operate with each other towards a common goal). The study involved subjects playing competitive games only.

Teenagers playing competitive video-gamer on a regular basis were found to have lesser scores in social intuition and hence were inept in dealing with social situations when compared to their peers. The striking outcome of the present study was the negative impact of competitive video-gaming on social intuition scores.

The questionnaire used to assess social intuition in the present study is based on Richard Davidson's theory of Emotional styles. In this theory he highlights the fact that different individuals respond to the same emotionally challenging situation in different ways and this constitutes the emotional style of an individual. This emotional style has six dimensions; Outlook, Resilience, Social Intuition, Self-Awareness, Sensitivity to Context and Attention, each one having its own unique 'neural signature'.

The dimension of social intuition is a measure of the ease with which a person can decipher non-verbal cues; it indicates how adept an individual is when dealing with a social situation. Being socially adept involves the ability to detect subtle facial expressions, body language or vocal intonation and infer social information from others' emotional states; it is the ability to tune with the emotional state of others. ${ }^{9}$

The findings of the present study are similar a study done by Weigman $\mathrm{O}$ et al., which showed a direct negative relationship between video-games and prosocial behavior. ${ }^{10}$ 
There are numerous studies claiming that violent competitive video-games have a negative impact on prosocial behavior and empathy and also negatively affect the behavior and attitude of teenagers. ${ }^{11,12,13}$

Moreover violent video-games have been shown to reduce sympathy, promote aggressive behavior and negatively impact moral judgment. ${ }^{14}$

However there are studies which have shown that co-operative video-games may in fact increase prosocial behavior and co-operation among the players, ${ }^{15}$ some video-games may even promote quick decision making and improve cognitive flexibility. ${ }^{16,17}$

When compared to outdoor games, video-games involve zero face to face interaction; this crucial factor may hamper the development of neuronal circuitry and the proper attitude essential for social intuition and prosocial behavior. We hypothesize that competitive video-games stimulate the inherent drive to win at all costs and thus trigger aggressive behavior among teenagers, making them less willing to co-operate and compromise in real life social situations.

We conclude that the effect of video-games mainly depends on the nature and type of video-games, with competitive/violent video-games negatively affecting social intuition and decreasing prosocial behavior in teenagers.

\section{Conclusion}

Competitive video-games seem to have a negative impact on social intuition scores as measured by emotional style questionnaire. Teenagers who regularly engage in competitive video-games seem to be less adept at deciphering non verbal communications and social cues.

With the increasing popularity of video-games and their rampant use among teenagers, video-games can no longer be dismissed as a harmless past-time. Parents, guardians and teachers must take into consideration the negative impact of video-games on social development and encourage teenagers to engage in outdoor games with their friends.

Limitations: The present study was done with a limited sample size; future cross-sectional studies with a larger sample size may shed new light on the findings of the present study.
Conflict of Interest: The authors declare that there are no conflicts of interest regarding the publication of this paper.

Acknowledgement: We are extremely grateful and indebted to Richard Davidson and Healthy Minds Innovations for the Emotional Style Questionnaire.

We also are grateful to all the volunteers who took part in the study.

Ethical Clearance: the study and its conduct were cleared by the ethical committee of the institute.

Source of Funding: Self

\section{References}

1. Yogman M, Garner A, Hutchinson J, Hirsh-Pasek K, Golinkoff RM. The Power of Play: A Pediatric Role in Enhancing Development in Young Children. Pediatrics 2018; 142 (3). e20182058

2. Vanderschuren LJ, Trezza V. What the laboratory rat has taught us about social play behavior: role in behavioral development and neural mechanisms. Curr Top BehavNeurosci. 2014; 16:189-212.

3. Desai RA, Krishnan-Sarin S, Cavallo D, Potenza MN. Video-gaming among high school students: health correlates, gender differences and problematic gaming. Pediatrics. 2010; 126(6):e1414-24.

4. Riess H. The Science of Empathy. J Patient Exp 2017; 4(2):74-77.

5. Kimmig AS, Andringa G, Derntl B. Potential Adverse Effects of Violent Video Gaming: Interpersonal- Affective Traits Are Rather Impaired Than Disinhibition in Young Adults. Front Psychol 2018; 9:736.

6. Mirjana Bajovic. Violent video gaming and moral reasoning in adolescents: is there an association? Educational Media International, 50:3, 177-191.

7. Hartmann T., Vorderer P. It's okay to shoot a character: moral disengagement in violent video games. Journal of communication 2010; 60: 94119.

8. Kühn S, Berna F, Lüdtke T, Gallinat J, Moritz S. Fighting Depression: Action Video Game Play May Reduce Rumination and Increase Subjective and Objective Cognition in Depressed Patients. Front Psychol. 2018; 9:129.

9. Richard J. Davidson. Well-being and affective 
style: neural substrates and biobehavioural correlates Phil. Trans. R. Soc. Lond. B 2004; 359: 1395-1411.

10. Wiegman O, Van Schie EG. Video game playing and its relations with aggressive and prosocial behaviour. Br J Soc Psychol 1998;37 (3):367-78

11. Anderson CA. An update on the effects of playing violent video games. J Adolesc. 2004; 27(1):11322.

12. Fraser AM, Padilla-Walker LM, Coyne SM, Nelson LJ, Stockdale LA. Associations between violent video gaming, empathic concern and prosocial behavior toward strangers, friends and family members. J Youth Adolesc. 2012; 41(5):636-49.

13. Gabbiadini A., Riva P., Andrighetto L., Volpato C., Bushman B. J. Interactive effect of moral disengagement and violent video games on self-control, cheating and aggression. Social
Psychological and Personality Science 2013; 4:451-458.

14. Bajovic M. (2013). Violent video gaming and moral reasoning in adolescents: is there an association? 50 177-191. 10.1080/09523987.2013.836367.

15. MengelF. Computer games and prosocial behaviour. PLo S One. 2014; 9(4):e94099. Published 2014 Apr 9. doi:10.1371/journal.pone.0094099.

16. Green CS, Pouget A, Bavelier D. Improved probabilistic inference as a general learning mechanism with action video games. Curr Biol. 2010 Sep 14; 20(17):1573-9.

17. Colzato LS, van Leeuwen PJ, van den Wildenberg WP, Hommel B. DOOM'd to Switch: Superior Cognitive Flexibility in Players of First Person Shooter Games. Front Psychol. 2010; 1:8. 